\title{
FINANCIAMENTO A INOVAÇÃO E INTERAÇÃO ENTRE ATIVIDADES CIENTÍFICAS E TECNOLÓGICAS: UMA ANÁLISE A PARTIR DO PAPPE
}

\author{
Pedro Henrique Torres ${ }^{\star}$ \\ Marisa dos Reis A. Botelho*
}

\section{Resumo}

A partir do enfoque de Sistemas Nacionais de Inovação, este trabalho tem como objetivo analisar o Programa de Apoio à Pesquisa em Empresas (PAPPE). Por meio de pesquisa direta nas empresas beneficiadas pelos recursos do Programa, são analisadas as características das empresas participantes; as relações de cooperação previamente estabelecidas à participação no PAPPE, bem como as relações geradas após a participação com diferentes agentes de inovação; os resultados obtidos com o projeto aprovado em termos de inovação. Como resultado principal, destaca-se que o PAPPE tem se mostrado importante na criação de inovações de produto para o mercado nacional e processos para o setor de atuação, por meio do fortalecimento e/ou fomento de relações de cooperação com agentes do sistema nacional de inovação.

Palavras-chave: inovação; políticas públicas; subvenção econômica; sistemas nacionais de inovação;

\begin{abstract}
This work aims to analyze a Brazilian public financing line to innovative projects, the Program to Support Research in Enterprises (PAPPE) - Portuguese: Programa de Apoio à Pesquisa em Empresas. An online questionnaire was developed to evaluate the contributions of the program, intending to characterize the beneficiated firms and identify the results on the creation of innovation, cooperation and other impacts on the performance of the firm. As main result, the work reveals that the PAPPE is important to create new products no the national market and new process to the sector, strengthening the relation between firms and other agents.
\end{abstract}

Keywords: innovation; public policy; subvention; national innovation systems;

Área 8 - Políticas de Ciência, Tecnologia e Inovação

Classificação JEL: $\mathbf{O}$ - Economic Development, Innovation, Technological Change, and Growth

\footnotetext{
- Mestre em Economia pelo Programa de Pós-graduação em Economia do Instituto de Economia da Universidade Federal de Uberlândia.E-mail: torres@mestrado.ufu.br.

• Professora Titular do Instituto de Economia da Universidade Federal de Uberlândia. E-mail: botelhomr@ufu.br.
} 


\section{Introdução}

Nas economias "baseadas no conhecimento", a produção, distribuição e uso do conhecimento e de informação são fatores fundamentais para o crescimento econômico, sendo necessários investimentos em Pesquisa e Desenvolvimento (P\&D), educação e treinamento. Portanto, investimentos em novos conhecimentos, bem como sua distribuição a partir de redes formais e informais, são essenciais para o desempenho de uma economia (OECD, 1996).

Os esforços das atuais políticas governamentais apontam para a modernização do capital humano buscando a promoção da capacidade de aprendizado, a distribuição do conhecimento na economia por meio de redes de colaboração e a difusão tecnológica. Em diferentes áreas, os formuladores de políticas têm de enfrentar desafios para compreender como a economia e a sociedade são influenciadas pelas mudanças tecnológicas, e para condução de pesquisas, bem como formulação de políticas, a abordagem de Sistema Nacional de Inovação (SNI) tem tido papel fundamental (OECD, 2002). Essa abordagem é definida como a rede de instituições nos setores público e privado cujas atividades e interações teriam como objetivo iniciar, importar, modificar e difundir novas tecnologias (FREEMAN, 1987).

A abordagem de SNI apoia-se no entendimento de que a inovação é fruto dos diferentes relacionamentos estabelecidos pelas empresas nos seus processos produtivo e inovativo, o que implica considerar os relacionamentos que envolvem a própria esfera produtiva, bem como as esferas social, institucional, política e financeira e as dimensões micro, meso e macro (EDQUIST, 2006). Nesse cenário é necessário apontar para o papel desempenhado pelas universidades e centros de pesquisas como agentes fundamentais nos sistemas de inovação nacionais e regionais, por serem capazes de formar mão de obra qualificada, e por serem fontes de conhecimento fundamental e conhecimento industrial para o setor de produção. A literatura sobre SNI enfatiza a importância de fortes ligações entre diferentes instituições a fim de se obter maior desempenho inovador e promover a melhoria na competitividade de um país (MOWERY; SAMPAT, 2004).

No entanto, o papel desempenhado por tais agentes difere de país para país, de região para região, bem como dentro de cada atividade de produção, com os sistemas universitários mantendo fortes características nacionais e refletindo contrastes marcantes se comparados na estrutura e influência histórica (MOWERY; SAMPAT, 2006; CASSIOLATO et al., 2007). O "Modelo de Hélice Tripla" (MHT), que investiga as relações de cooperação entre universidade, indústria e governo, coloca a infraestrutura científico-tecnológica como agente essencial em economias baseadas no conhecimento, abrindo-se as portas para a universidade desempenhar um importante papel no desenvolvimento econômico (ETZKOWITZ; LEYDESDORFF, 2000).

A partir disso, é importante destacar o caráter que as políticas tecnológicas têm assumido, dando maior importância às relações de interação, geração e difusão de conhecimento; por consequência, buscase a criação de uma infraestrutura de fomento de modo a ampliar e aprimorar os relacionamentos entre diferentes agentes. Este trabalho tem como objetivo avaliar uma linha de financiamento público - o Programa de Apoio à Pesquisa em Empresas (PAPPE), lançado no final de 2003, a partir de uma ação conjunta entre a Financiadora de Estudos e Projetos (FINEP) e as Fundações de Amparo à Pesquisa estaduais (FAPs), visando o apoio financeiro a projetos inovadores.

Analisa-se o PAPPE a partir das características das empresas que tiveram projetos aprovados em diferente editais lançados pelas FAPs de alguns estados brasileiros; das relações de cooperação previamente estabelecidas à participação no PAPPE, bem como das relações geradas após a participação, em especial com agentes diretos da inovação; dos resultados obtidos com o projeto aprovado em termos de inovações e impactos nos indicadores econômicos. Esses itens serão analisados na seção 4 do trabalho, que apresentam os dados e a discussão. Na sequência, apresenta-se a revisão de literatura, na seção 2, a metodologia, na seção 3 e, por último, as principais conclusões.

\section{Revisão da literatura}

Ao ampliarem seus canais de geração e acesso ao conhecimento tecnológico, as empresas são capazes de atingirem níveis mais elevados de inovação, investindo em P\&D e articulando-se com fontes externas de tecnologia. Esta última relaciona-se com a complexidade crescente da tecnologia aplicada a produtos e serviços, tornando fundamentais as diversas modalidades de aprendizado interativo, entre 
empresas e entre estas e outras instituições. As interações entre o setor acadêmico e o produtivo têm se intensificado, e crescentemente apoiadas por políticas públicas, de modo que as universidades são vistas como atores institucionais cruciais nos sistemas nacionais de inovação (MOWERY;SAMPAT, 2006).

No modelo de Hélice Tripla, as formas mais tradicionais de relação universidade-empresa (U-E), como consultoria e ligações que incentivam o fluxo de conhecimento, tornaram-se menos importantes com o aumento do número de empresas que buscam fontes de P\&D externo. As relações formais se intensificam, com as empresas externalizando o processo de $P \& D$ em busca de insumos mais tangíveis de fontes como as universidades (ETZKOWITZ, 1998; 2009). Segundo este autor, as antigas formas de interação U-E envolviam o pagamento por serviços prestados (de forma direta) ou doação de recursos (indiretamente), enquanto as novas formas de cooperação entre os dois agentes envolvem a multiplicação de recursos através da universidade e participação de pesquisadores em projetos industriais. De acordo com Etzkowitz e Leydesdorff (2000), MHT propõe que a universidade possui capacidade para reforçar a inovação em sociedades cada vez mais baseadas no conhecimento ao atuar conjuntamente com a indústria e o governo.

A premissa do modelo é a existência de oportunidades comerciais conhecidas por cientistas engenheiros e demais profissionais, sendo os dois primeiros conjuntos importantes para o desenvolvimento de empresas baseadas no conhecimento e o último, o conjunto de fatores que aumentam as chances de uma estratégia de desenvolvimento econômico baseada em conhecimento. Nas interações da Hélice Tripla, universidade, empresas e governos assumem o "papel do outro", mesmo mantendo seus papeis primários e suas identidades distintas. Ao estimular o desenvolvimento de empresas a partir da pesquisa, as universidades assumem o papel da indústria (capitalização do conhecimento); a partir de joint ventures, as empresas desenvolvem treinamentos e compartilham conhecimento, aproximando-se das funções do meio acadêmico; já os governos agem como capitalistas públicos do ao apoiar diferentes interações, ao mesmo tempo em que mantêm a atividade regulatória (ETZKOWITZ, 2009).

No cenário brasileiro, as relações U-E não apresentam um circuito retroalimentador, onde fluxos de informações e de conhecimento transitam entre universidades e empresas, em ambos os sentidos, de modo que a literatura aponta para um padrão de interação caracterizado por "pontos de interação" (RIGHI; RAPINI, 2011; RAPINI, 2007). Consoante Suzigan e Albuquerque (2011), o caráter tardio da criação de instituições de ensino e pesquisa e universidades no país, junto à industrialização tardia, justifica a baixa interação entre ciência e tecnologia. Ademais, outros aspectos têm sido discutidos em trabalhos recentes, referentes às suas naturezas distintas, à presença de desconfiança mútua e choques culturais, que fazem com que seus objetivos não coincidam, de modo que cada parte desempenha seu papel separadamente (NOVELI; SEGATTO, 2012; IPIRANGA et al., 2010; PLONSKI, 1994; SBRAGIA, 2006).

Os problemas mais comuns nas interações U-E no país no período recente são encontrados: i) no baixo conteúdo científico e curto prazo requerido para as soluções industriais, que não estimulam os contratantes a investirem em P\&D; ii) na ausência de interlocutores adequados nas empresas dificultando a comunicação; iii) no setor produtivo pouco inovativo; iv) na ausência de instrumentos adequados nas universidades para a comercialização de tecnologia; v) na pouca flexibilidade das instituições de C\&T (RIGHI; RAPINI, 2011). A forma como se desenvolveram as relações U-E no Brasil contribuem, dentre outros, para a caracterização do sistema de inovação brasileiro como imaturo ou incompleto, de modo que a fragilidade dos laços de interação entre o setor de produção e a ciência se configura como uma das lacunas que precisam ser superadas pelo Brasil para a consolidação do seu sistema de inovação (RAPINI et al., 2009; STAL; FUJINO, 2005; SUZIGAN; ALBUQUERQUE, 2011).

Para o desenvolvimento de um SNI, faz-se necessário a existência de instituições que exerçam um papel viabilizador para o investimento, não apenas para crescimento econômico de modo geral, mas em particular para a inovação. De outro modo, a maneira como as estruturas financeiras se articulam define as trajetórias de desenvolvimento, impactando diretamente no SNI, de modo que a ausência de um sistema financeiro com funcionalidade impeça o seu amadurecimento (ALBUQUERQUE, 1996).

Corder (2004) resume algumas características necessárias para um Sistema de Inovação ser “orgânico": i) organizações de ensino e pesquisa produzindo conhecimentos e tecnologias e que mantenham um bom nível de cooperação com as organizações empresariais e geradoras potenciais de 
inovação e também produtoras de pesquisas e de tecnologias; ii) um sistema produtivo que, induzido pela concorrência ou por estratégias empresariais de médio e longo prazo, introduza sistematicamente inovações de processo e produto a partir da implementação de atividades de P\&D, como parte deste esforço de inovação; iii) um conjunto de instituições de prestação de serviços tecnológicos e suporte à infraestrutura tecnológica; iv) um sistema de informações e de indicadores estruturado; v) órgãos reguladores e normas; vi) suporte financeiro; vii) coordenação tanto por parte do mercado quanto por parte do Estado. Para a autora, tais elementos devem operar de maneira sistêmica, no entanto, aponta que é algo não trivial, de modo que no cenário brasileiro tais atores estão presentes, há infraestrutura de apoio, mas a cooperação entre eles e a coordenação a partir da ação do Estado são restritas.

Mazzucato (2011) argumenta que o papel do governo nas economias bem sucedidas tem ido além da criação de uma infraestrutura e definição das regras a serem seguidas, agindo como o principal agente para se alcançar avanços que permitem às empresas e economias crescerem e criarem condições de desenvolvimento de inovações. A autora defende a necessidade de entender a inovação como um processo coletivo, com o Estado desenvolvendo a base do processo de inovação ao fazer investimento em infraestrutura física e humana, que por vezes indivíduos e empresas seriam incapazes de financiar devido à combinação do montante dos custos fixos com o grau de incerteza que este investimento implica. Ademais, o Estado também tem papel importante ao subsidiar investimentos que permitem aos funcionários de empresas participar do processo de inovação com pesquisadores acadêmicos interagindo no processo de criação de conhecimento.

Segundo Freeman e Soete (2008), o fracasso no processo inovativo pode ocorrer por três motivos: i) incertezas técnicas; ii) incertezas de mercado; iii) incertezas gerais, políticas e econômicas (incertezas de negócios). Tanto as incertezas técnicas como as de mercado possuem características próprias a cada projeto de inovação, de modo que não se pode calculá-las, descontá-las ou eliminá-las. Os autores ainda apontam que as incertezas técnicas podem diminuir nos estágios iniciais de um projeto em desenvolvimento e durante os testes de produção, no entanto, os resultados encontrados nessas duas etapas não são conhecidos até que cada etapa tenha sido desenvolvida, a fim de caracterizar um experimento e uma atividade verdadeiramente inovativa.

Esses autores apresentam diferentes graus de incerteza associado a vários tipos de inovação: i) incertezas verdadeiras (pesquisa e inventos fundamentais); ii) níveis muito altos de incerteza (inovações radicais de produtos e processos realizadas fora da firma); iii) altos níveis de incerteza (importantes inovações de produto e inovações radicais de processos obtidas no próprio estabelecimento ou contexto da firma); iv) incerteza moderadas (novas "gerações” de produtos já existentes); v) pouca incerteza (inovações licenciadas, imitações de inovações de produtos e adoção antecipada de processos já existentes); vi) muito pouca incerteza (novos “modelos”, diferenciação de produtos, providência para inovação de produtos já existentes, adoção tardia de inovações de processos já existentes e de operações franqueadas no próprio estabelecimento e melhorias técnicas). "Por definição, as inovações não constituem uma classe homogênea de eventos, mas algumas categorias de inovações são reconhecidamente menos incertas que outras e, portanto, menos arriscadas” (FREEMAN; SOETE, 2008, p.416). De acordo com os autores, mesmo nos níveis mais baixos de incerteza há uma proporção muito pequena de $P \& D$ que é diretamente financiada pelo mercado de capitais, predominando recursos financeiros internos. Desta maneira, se o risco não for assumido pela empresa ou por terceiros que tenham interesse no projeto, torna-se necessário algum meio que cubra os custos e uma remuneração, que pode ser por meio de financiamento ou posse total da infraestrutura de P\&D pelo governo.

Consoante Rapini (2010), há diferentes maneiras para financiar a inovação, podendo partir da esfera pública, da esfera privada, ou até mesmo de uma relação entre ambas. Em muitos países a esfera pública conduz o investimento de longo prazo a partir de: i) programas de incentivo à atividade de $P \& D$ (empréstimos, incentivos fiscais e recursos não reembolsáveis); ii) recursos para financiamento de $P \& D$ por meio de programas de compras governamentais; iii) auxílio à infraestrutura de $\mathrm{P} \& \mathrm{D}$ visando o desenvolvimento da indústria. "O financiamento à inovação, na maioria dos países, conta com recursos públicos e com a atuação do governo” (RAPINI, 2010, p.43), sendo os incentivos fiscais às atividades de P\&D o instrumento mais antigo, com uma tendência a favorecer empresas já estabelecidas. De outro modo, os incentivos não fiscais focam em estudos de viabilidade, desenvolvimento de protótipos, 
comercialização etc., além de apoiar as micro e pequenas empresas (MPEs) e empresas de base tecnológica.

De um lado, os incentivos fiscais são explicitados em legislação específica, o que os torna mais acessíveis, de outro, os incentivos não fiscais são praticados sem necessidade de um arcabouço legal, de modo que nem sempre são visíveis e possuem objetivos claros (LONGO et al., 2002). De modo geral, tais incentivos visam diminuir custos e/ou riscos, tornando-os mais atrativos, estimulando a busca de inovações pelas empresas.

Os custos de desenvolvimento tecnológico do setor produtivo a partir da participação ou compartilhamento governamental, de modo parcial ou total, é outra modalidade de apoio utilizada, podendo assumir a forma de bolsas e/ou recurso não reembolsáveis (vinculada a determinadas etapas do processo de inovação), participação parcial direta, ou a partir de encomenda e custeio das atividades necessárias para o desenvolvimento de produtos e processos (transferência de riscos para o setor público, diminuição ou retirada dos custos de desenvolvimento do preço final do produto, ressarcimento posterior dos custos de desenvolvimento mediante os royalties incidentes sobre a venda dos produtos, por exemplo), participação total do governo (LONGO et al. 2002; RAPINI, 2010).

Dentre os recursos da modalidade não reembolsável quatro podem ser destacados conforme aponta Rapini (2010): bolsas, auxílios, capital de risco e subvenção econômica. Os dois primeiros concentram-se em instituições de pesquisa e universidades para desenvolvimento de projetos cooperativos com o setor industrial visando inovação de produtos e processos produtivos; os outros dois se destinam à aplicação de recursos diretamente nas empresas.

Especificamente, a subvenção econômica é praticada por diversos países desenvolvidos e emergentes, operada de acordo com as normas da Organização Mundial do Comércio (OMC), e o agente que o recebe não precisa devolver o valor recebido. É um instrumento utilizado para o financiamento de ações que impactam positivamente a sociedade, de modo que o ofertante entende que os resultados criados a partir do financiamento lhe criarão benefícios posteriormente.

A Lei do Bem e a Lei de Inovação constituíram o marco regulatório que viabiliza a concessão de subvenção econômica no Brasil ${ }^{1}$. Assim, busca-se um novo ambiente vocacionado para a promoção da inovação em empresas brasileiras, no qual a Financiadora de Estudos e Projetos (FINEP) se apresenta como principal agente. A Lei de Inovação, especificamente, dentre seus diversos itens, prevê a concessão de recursos financeiros por parte da União para a promoção do desenvolvimento de produtos e processos em empresas nacionais.

Além da ação do Governo Federal para fomento à inovação tecnológica, os governos estaduais desenvolvem seus respectivos sistemas estaduais de inovação. Segundo Weisz (2006), o mais antigo e bem consolidado desses é o do Estado de São Paulo que, a partir da Fundação de Apoio à Pesquisa do Estado de São Paulo (FAPESP), apoia as atividades de pesquisa no estado. Desde 1989, diversos estados incluíram em suas novas constituições estaduais artigos com foco no esforço científico e tecnológico, com diversos deles criando suas respectivas Fundações de Apoio à Pesquisa (FAPs).

Dentre as iniciativas que envolvem os sistemas estaduais na inovação tecnológica, encontra-se o Programa de Apoio à Pesquisa em Empresas (PAPPE), que tem como objetivo promover o desenvolvimento tecnológico das empresas, induzindo-as a se relacionarem com instituições de ensino e pesquisa para a geração de inovações tecnológicas. Lançado no final de 2003, a partir de uma ação conjunta entre a Financiadora de Estudos e Projetos (FINEP) e as Fundações de Amparo à Pesquisa estaduais (FAPs), seu principal objetivo centra-se no apoio financeiro a projetos inovadores. O Programa surge da necessidade de fortalecer o Sistema Nacional de Inovação Brasileiro (SNIB) aumentando a competitividade das empresas a partir da colaboração efetiva entre distintos agentes de inovação, e sua proposta "se circunscreve na adoção de uma política de C,T\&I mais pragmática que busca a articulação

\footnotetext{
${ }^{1}$ Segundo a FINEP: “O marco regulatório que viabiliza a concessão de subvenção econômica foi estabelecido a partir da aprovação da Lei 10.973, de 02.12.2004, regulamentada pelo Decreto 5.563, de 11.10.2005 (LEI DA INOVAÇÃO), e da Lei 11.196, de 21.11.2005, regulamentada pelo Decreto no. 5.798 de 07 de junho de 2006 (LEI DO BEM). Esse novo cenário é vocacionado para a promoção da inovação nas empresas no País e tem na Finep, empresa pública vinculada ao Ministério de Ciência e Tecnologia, seu principal agente.” <Disponível em: http://www.finep.gov.br/apoio-e-financiamentoexterna/instrumentos-de-apoio/subvencao-economica>
} 
entre atores com o intuito de promover na sociedade condições mais favoráveis à aproximação do setor produtivo com o setor de pesquisa” (LIMA et al. 2014, p. 5).

\section{Metodologia}

Para cumprir com os objetivos propostos foi desenvolvida uma pesquisa intitulada "Interação PAPPE”, composta de duas fases. A primeira constituiu-se de um questionário on line, reproduzindo questões utilizadas na pesquisa conduzida por Carrijo $(2011)^{2}$. São questões relacionadas às características das empresas, suas atuações antes da participação no programa, aspectos relacionados ao projeto desenvolvido e os impactos do Programa sobre a firma. Posteriormente, buscou-se a realização de entrevistas com os coordenadores das empresas que responderam ao questionário on line, a fim de se captar maiores informações a respeito das dificuldades encontradas durante a execução do programa, as fontes de conhecimento externas e as relações desenvolvidas pelas empresas com outros agentes e os desdobramentos do PAPPE dentro da firma. Neste artigo, a análise centra-se nos dados obtidos na primeira etapa.

A partir de contatos com 20 FAPs estaduais e/ou análise dos resultados das chamadas dos editais do PAPPE em seus respectivos sítios eletrônicos, foi possível identificar a participação de 835 empresas, que representam 870 projetos aprovados no Programa. Desse total, foram contatadas 304 empresas, dentre as quais 4 recusaram-se a responder, 8 responderam ao questionário de maneira incompleta, não sendo possível incorporar à análise, 5 ignoraram a pesquisa e 222 não retornaram o contato em nenhum momento $^{3}$. Um total de 65 empresas responderam ao questionário online de maneira completa ${ }^{4}$. Essas empresas estão distribuídas em 14 das unidades federativas brasileiras (AM, BA, DF, CE, MA, MG, MT, PB, PE, PR, RJ, RS, SC, SP), que abrangem as cinco macrorregiões brasileiras e foram observadas participações em 26 diferentes editais lançados pelas FAPs dos respectivos estados, com 25\% das empresas tendo participado em mais de um edital. Assim, embora sejam 65 empresas participantes, ao todo são contabilizados 83 projetos. Em relação à segunda fase, foi possível entrevistar, de maneira não presencial, 5 das 65 empresas participantes ${ }^{5}$.

\section{Análise dos resultados da pesquisa}

\subsection{Caracterização das empresas e sua participação no PAPPE}

As empresas participantes da pesquisa são relativamente jovens, dado que $33 \%$ possuem no máximo dez anos em atividade. Apenas 27\% delas surgiram antes da década de 2000, sendo o decênio posterior o mais representativo da amostra, com 58\% das empresas iniciando suas operações. As mais novas, fundadas a partir de 2010 representam 12\% do total.

Essas empresas, em geral, possuem profissionais com no mínimo o ensino superior completo. Em relação à especialização ou MBA, 58\% delas alegaram ter ao menos um profissional com esta modalidade de pós-graduação. Considerando a mesma análise para Mestrado, Doutorado e Pós-doutorado, estes números representam 65\%, 32\% e 17\%, respectivamente. Isso indica que as empresas participantes do programa contam com profissionais capacitados para execução de suas atividades.

\footnotetext{
${ }^{2}$ A pesquisa conduzida por Carrijo (2011) restringiu-se aos Estados de Minas Gerais, Rio de Janeiro e São Paulo, enquanto a presente pesquisa possui abrangência nacional.

${ }^{3}$ A diferença entre empresas identificadas (835 empresas) e empresas contatadas (304 empresas) deve-se à dificuldade em encontrar um meio de contato. Embora algumas FAPs tenham fornecido algum tipo de contato, realizou-se uma busca em sites de pesquisa por cada um das empresas beneficiadas, não sendo possível ter acesso ao site em mais da metade delas.

${ }^{4}$ O questionário foi desenvolvido a partir da SurveyMonkey, uma companhia baseada em nuvem de desenvolvimento de pesquisas on line, e ficou disponível do período correspondente a 17 de Maio de 2015 a 16 de Agosto de 2015 e de 02 de Setembro de 2015 a 01 de Dezembro de 2015, mediante assinatura do plano de acesso.

${ }^{5}$ Neste trabalho não serão descritos os casos individualmente, mas tão somente serão apresentadas as informações que são capazes de suportar a proposta aqui desenvolvida. Esta fase da Interação PAPPE contou com a participação de 5 empresas que responderam à questões relacionadas à aplicação do recurso, aos objetivos traçados, aos desdobramentos do projeto, à participação em outras fontes de recursos, às relações de cooperação, às inovações e aos impactos sobre a firma. Quando necessário, as empresas serão nomeadas da seguinte maneira: Alfa, Beta, Gama, Delta e Épsilon.
} 
Cerca de $60 \%$ das empresas estão localizadas em capitas das unidades federativas do Brasil, com destaque para as cidades de Fortaleza, Manaus, Recife, Salvador, São Paulo e Belo Horizonte, que juntas representam 49\% da amostra. Apenas 22 empresas estão localizadas em cidades com menos de 1 milhão de habitantes, sendo 36\% dessas inseridas em regiões com menos de 100 mil habitantes. Em relação ao principal mercado, 69\% têm o nível nacional como seu maior alcance, enquanto os níveis local, regional e estadual são os principais mercados de $8 \%, 14 \%$ e $7 \%$ das firmas entrevistadas, respectivamente. Apenas uma empresa declarou ter no setor externo seu principal mercado. Ademais, apenas $26 \%$ exportam, com a maioria destinando cerca de $1 \%$ a $10 \%$ das vendas ao mercado exterior. Para identificação do segmento de atividades das empresas, utilizou-se a classificação de “divisão” de acordo com a Classificação Nacional de Atividades Econômicas (CNAE) (Tabela 1). Nas 2 primeiras colocações, como esperado, estão setores que podem ser classificados como "Intensivos em Ciência", da taxonomia de Pavitt (1984).

\begin{tabular}{c|c}
\hline \multicolumn{2}{c}{ Tabela 1 - Setor declarado pela empresa segundo classificação CNAE (\%) } \\
\hline Setor & $\%$ \\
\hline Atividades de informática e serviços relacionados & $21,54 \%$ \\
\hline Pesquisa e desenvolvimento & $13,85 \%$ \\
\hline Fabricação de produtos alimentícios e bebidas & $10,77 \%$ \\
\hline Fabricação de máquinas equipamentos & $7,69 \%$ \\
\hline Saúde e serviços sociais & $7,69 \%$ \\
\hline Serviços prestados principalmente às empresas & $6,15 \%$ \\
\hline Agricultura, pecuária e serviços relacionados & $4,62 \%$ \\
\hline Fabricação de material eletrônico e de aparelhos e equipamentos de comunicações & $4,62 \%$ \\
\hline Fabricação de produtos químicos & $4,62 \%$ \\
\hline Silvicultura, exploração florestal e serviços relacionados & $4,62 \%$ \\
\hline Fabricação de equipamentos de instrumentação médico hospitalares & $3,08 \%$ \\
\hline Fabricação de produtos de metal - exceto máquinas e equipamentos & $3,08 \%$ \\
\hline Extração de petróleo e serviços relacionados & $3,08 \%$ \\
\hline Fabricação de produtos de minerais não-metálicos & $1,54 \%$ \\
\hline Reciclagem & $1,54 \%$ \\
\hline Fonte: Pesquisa de camuinas, aparelhos e materiais elétricos & $1,54 \%$ \\
\hline
\end{tabular}

Fonte: Pesquisa de campo (2015)

São três os motivos destacados pelas empresas para a participação no PAPPE: a subvenção econômica, a participação em outros editais de fomento e a divulgação dos editais por parte das FAPs estaduais, apontadas por $48 \%, 42 \%$ e $38 \%$, respectivamente. Pode-se então sugerir que são empresas que buscam auxílio para conduzirem seus projetos e que demonstram estarem ligadas aos programas de apoio. Apenas 1\% das empresas alegou não conhecer nenhum outro programa de apoio. O mesmo percentual indica que o PAPPE não é preterido a outros programas de fomento por ser menos exigente, talvez porque são poucos os programas com as mesmas características no período recente, de modo que um edital com altas exigências não seria realmente uma barreira para buscar a participação no mesmo, principalmente quando se trata de recursos não reembolsáveis.

A maior parte das empresas tomou conhecimento do Programa a partir do próprio site da FAP de seu respectivo estado, cerca de $45 \%$, seguido do meio acadêmico com $22 \%$. Além disso, as empresas costumam manter uma relação muito boa com a FAP de seu estado, com os três graus mais positivos apresentando os maiores percentuais $25 \%$ avaliando como "boa relação", 37\% como "muito boa relação" e 25\% como "excelente relação". Mesmo que a atuação de uma FAP em relação à outra varie, fica evidente o bom relacionamento desses agentes com as empresas que buscam seu apoio.

No que se refere à relação com o pesquisador envolvido no projeto, $70 \%$ das empresas alegaram que já mantinham relação com o mesmo, enquanto as demais construíram a relação em virtude da 
participação no PAPPE. Em relação a este tipo de relacionamento, apenas 17\% das empresas alegaram que esses pesquisadores faziam parte do seu pessoal ocupado, enquanto 34\% das empresas conduziram projetos com envolvimento de pesquisadores de universidades federais. Os pesquisadores de institutos de pesquisa aparecem com apenas 11\%, atrás de universidades públicas estaduais e até mesmo de instituições de ensino particulares, o que corrobora a tendência dessas empresas a buscarem relacionamentos com universidades; os demais pesquisadores, representando $5 \%$, não pertenciam à empresa ou mesmo eram membros de alguma ICT. Para as empresas, a presença do pesquisador é de grande importância para o desenvolvimento do projeto, o que nos diz que a capacitação de mão-obra para condução de projetos de inovação é um fator determinante e que pode servir para a inclusão de pesquisadores no setor produtivo brasileiro. Ademais, cerca de $37 \%$ das empresas apenas necessitaram de contratação de pesquisas complementares, enquanto apenas 31\% delas tiveram de contratar pesquisas que elas e o pesquisador não poderiam executar.

Dentre as dificuldades encontradas para se adequar às exigências da FAP, destacadas na Tabela 2, apenas uma é considerada pouco relevante pela maioria, que diz respeito justamente ao desenvolvimento do projeto; ainda assim, deve-se atentar que o percentual dessa dificuldade se encontra extremamente próximo do grau relevante. Considerando os graus mais elevados, as dificuldades mais destacadas foram o alinhamento do projeto com o orçamento disponível e a realização de viabilidade técnica, econômica e comercial. Tais resultados podem estar ligados à falta de formação de gestão necessária para a participação em programas de apoio público. De modo geral, as dificuldades estão concentradas nos graus pouco relevante/relevante, de modo que se pode considerar que parte das empresas consegue reunir competências e expertise para acessar recursos públicos, enquanto outras precisam enfrentar maiores barreiras. Como cerca de $70 \%$ das empresas já mantinham relacionamento com os pesquisadores associados ao projeto, o fato de 37\% delas alegarem que encontrar o pesquisador que atue na mesma área que a empresa para estabelecer a parceria foi uma dificuldade considerável(20\% colocaram como uma dificuldade muito relevante), é algo contraditório, uma vez que se esperava que tal dificuldade estivesse concentrada nos graus irrelevante/pouco relevante.

Tabela 2 - DIFICULDADES para se adequar às exigências da FAP para submeter um projeto ao edital PAPPE de acordo com o seu grau de relevância (\%)

\begin{tabular}{l|c|c|c|c}
\hline \multicolumn{1}{c|}{ Dificuldades } & Irrelevante & $\begin{array}{c}\text { Pouco } \\
\text { relevante }\end{array}$ & Relevante & $\begin{array}{c}\text { Muito } \\
\text { relevante }\end{array}$ \\
\hline $\begin{array}{l}\text { Encontrar o pesquisador que atue na mesma área que a } \\
\text { empresa para estabelecer a parceria }\end{array}$ & $25 \%$ & $18 \%$ & $37 \%$ & $20 \%$ \\
\hline Desenvolver o projeto & $11 \%$ & $35 \%$ & $34 \%$ & $20 \%$ \\
\hline Reunir a documentação exigida & $8 \%$ & $32 \%$ & $43 \%$ & $17 \%$ \\
\hline Estabelecer a contrapartida da empresa & $12 \%$ & $34 \%$ & $43 \%$ & $11 \%$ \\
\hline $\begin{array}{l}\text { Fazer o estudo de viabilidade técnica, econômica e } \\
\text { comercial }\end{array}$ & $8 \%$ & $25 \%$ & $49 \%$ & $18 \%$ \\
\hline $\begin{array}{l}\text { Desenvolver um orçamento compatível com o objetivo } \\
\text { proposto pelo projeto }\end{array}$ & $8 \%$ & $19 \%$ & $42 \%$ & $31 \%$ \\
\hline
\end{tabular}

Fonte: Pesquisa de campo (2015)

Quando analisamos as empresas a partir de dois grupos (relação já existia e relação surgiu com o PAPPE) os seguintes resultados aparecem: i) primeiro grupo - $55 \%$ das empresas consideram tal dificuldade pouco relevante ou irrelevante, enquanto 33\% destacaram que foi uma dificuldade relevante; ii) segundo grupo - apenas $26 \%$ das que criaram o relacionamento devido ao PAPPE encontraram baixa dificuldade em alinhar com sua área de pesquisa. Assim, de modo geral as empresas destacam certa dificuldade em encontrar pesquisadores que atuem na mesma área, mesmo quando a relação já existia, o que pode sugerir que tais empresas se adaptam com a capacitação do profissional disponível.

A Tabela 3, por sua vez, apresenta os obstáculos que prejudicaram a implementação do projeto, destacando-se dois: a demora na liberalização dos recursos (de alta importância) e a falta de mão de obra qualificada. A falta de infraestrutura foi uma dificuldade para cerca de $31 \%$ das empresas, com $60 \%$ 
dessas considerando uma dificuldade relevante. Vale ressaltar que $73 \%$ das empresas utilizaram infraestrutura própria na execução do projeto, $11 \%$ de universidades, $8 \%$ das incubadoras, $1 \%$ de institutos de pesquisa, $1 \%$ de empresas concorrentes e $6 \%$ de outros agentes.

Tabela 3 - Dificuldades/obstáculos que prejudicaram a implementação do projeto PAPPE e o seu grau de relevância (\%)

\begin{tabular}{l|c|c|c|c|c|c}
\hline \multicolumn{1}{c|}{ Impactos } & \multirow{2}{*}{ Sim } & \multicolumn{3}{c}{ Grau de Relevância } \\
\cline { 4 - 6 } & & Irrelevante & $\begin{array}{c}\text { Pouco } \\
\text { relevante }\end{array}$ & Relevante & $\begin{array}{c}\text { Muito } \\
\text { Relevante }\end{array}$ & Não \\
\hline Demora na liberação dos recursos financeiros & $54 \%$ & $0 \%$ & $6 \%$ & $54 \%$ & $40 \%$ & $46 \%$ \\
\hline Falta de infraestrutura adequada & $31 \%$ & $0 \%$ & $25 \%$ & $60 \%$ & $15 \%$ & $69 \%$ \\
\hline $\begin{array}{l}\text { Falta de cooperação com outras } \\
\text { empresas/instituições }\end{array}$ & $25 \%$ & $0 \%$ & $13 \%$ & $63 \%$ & $24 \%$ & $75 \%$ \\
\hline Falta de insumos de produção & $25 \%$ & $0 \%$ & $31 \%$ & $44 \%$ & $25 \%$ & $75 \%$ \\
\hline Falta de mão de obra qualificada & $52 \%$ & $0 \%$ & $9 \%$ & $47 \%$ & $44 \%$ & $48 \%$ \\
\hline $\begin{array}{l}\text { Dificuldade para se adequar a padrões, normas e } \\
\text { regulamentações }\end{array}$ & $31 \%$ & $0 \%$ & $10 \%$ & $70 \%$ & $20 \%$ & $69 \%$ \\
\hline $\begin{array}{l}\text { Ausência de bom relacionamento entre empresa } \\
\text { e pesquisador }\end{array}$ & $5 \%$ & $0 \%$ & $34 \%$ & $66 \%$ & $0 \%$ & $95 \%$ \\
\hline $\begin{array}{l}\text { Prazo muito curto para o desenvolvimento do } \\
\text { projeto }\end{array}$ & $34 \%$ & $0 \%$ & $23 \%$ & $45 \%$ & $32 \%$ & $66 \%$ \\
\hline
\end{tabular}

Fonte: Pesquisa de campo (2015)

Algumas dificuldades com baixo percentual se relacionam com dados apresentados anteriormente: apenas $25 \%$ das empresas apresentaram dificuldades de cooperação com outras empresas e instituições ou mesmo falta de insumos de produção, o que indica que as relações com os agentes acadêmicos e os fornecedores, sobretudo a partir do grau de formalização, são fatores que impactaram positivamente a implementação do projeto aprovado no PAPPE. A relação com o pesquisador também não foi uma dificuldade que as empresas encontraram, dado que apenas 5\% delas declararam haver ausência de bom relacionamento com o pesquisador associado, o que também sugere que os relacionamentos já existentes influenciem nesse aspecto.

\subsection{P\&D e Inovação}

As atividades de $P \& D$ são de suma importância e parcerias são componentes fundamentais para a potencializar contribuição do pessoal envolvido em P\&D. Nos países da OECD, emprego de pesquisadores em tais atividades tem aumentado na última década, elevando o número de pesquisadores em relação ao restante do pessoal ocupado nas empresas. Em países como Israel, Japão, Coreia do Sul e Suécia a quota de pesquisadores atuando no setor empresarial é superior a $65 \%$, considerando todo o pessoal ocupado envolvido em P\&D (OECD, 2015). A ciência torna-se cada vez mais ativa no processo de inovação, e estudos indicam que a presença de um departamento de $\mathrm{P} \& \mathrm{D}$, com empresas realizando todo o processo inovativo até a pesquisa aplicada e desenvolvimento de produtos e processos, favorece as empresas inovativas perante aquelas que não possuem um departamento de P\&D (OECD, 2010).

Na PINTEC 2011, o setor de Serviços apresentou o maior percentual de empresas que desempenhavam atividades e que possuíam um departamento de $\mathrm{P} \& \mathrm{D}$, com $31,7 \%$ das empresas atribuindo importância como uma fonte de informação para inovações, sublinhando o caráter intensivo em conhecimento em determinados segmentos do setor. Dentre as empresas do setor de Eletricidade e gás, 26,9\% atribuíram importância às informações vindas do departamento de $\mathrm{P} \& \mathrm{D}$, enquanto na indústria o percentual é menor, com 14,2\% atribuindo importância (PINTEC, 2011).

Considerando o período anterior ao PAPPE, cerca de 58\% das empresas mantinham um grau de frequência contínuo em relação ao desenvolvimento de atividades inovativas, enquanto $23 \%$ investiam de 
maneira ocasional e $19 \%$ não o faziam. Mais da metade das empresas, cerca de $60 \%$, mantinham um baixo gasto médio anual com este tipo de atividade, variando de 0 a $\mathrm{R} \$ 80.000$. Em relação à presença de um departamento de $P \& D$, 54\% declarou possuir, enquanto 17\% utilizavam de uma incubadora, $20 \%$ de uma universidade e $9 \%$ de um instituto de pesquisa. A aquisição externa de P\&D, foi considerada por $57 \%$ das empresas como um elemento relevante para as suas atividades inovativas, enquanto $43 \%$ consideram irrelevante ou pouco relevante. No entanto, não se pode atentar apenas para uma visão de dependência tecnológica, uma vez que compra externa de P\&D é um mecanismo capaz de reduzir custos com pesquisa aplicada, visando à promoção de inovações (CARRIJO; BOTELHO, 2013). Sobre o grau de absorção de informações tecnológicas, apenas 6\% consideram-no como baixo, 53\% como médio e $41 \%$ como alto.

Em relação às inovações introduzidas nas empresas no período pré-PAPPE, apenas dois impactos não foram observados em mais da metade das empresas: a entrada no mercado externo e a redução dos custos de produção. No entanto, a redução de custos manteve um percentual pouco abaixo da metade (43\%), com avaliações de cunho positivo pelas empresas que o fizeram, de modo que apenas a entrada no mercado externo se mostrava como uma barreira que as empresas não conseguiam ultrapassar. Dentre os impactos que já eram observados, em mais da metade da amostra, encontram-se: i) melhora na qualidade do produto para 89\%; ii) ampliação da gama de produtos ou serviços ofertados para 82\%; iii) permitiu à permanência da participação no mercado para 72\%; iv) promoveu maior inserção no mercado nacional para 65\%; v) criou novas oportunidades de negócios para 88\%; vi) aumentou a produtividade em 68\% das empresas; vii) aumentou a capacitação de recursos humanos para $65 \%$ do total.

Durante o desenvolvimento da pesquisa, a maior parte das empresas já havia finalizado seus projetos, com alguns casos específicos: i) algumas empresas da Bahia, participantes do edital de 2011 lançado pela FAPESB, alegaram estar finalizando seus projetos, os quais já haviam gerado produto, mas o mesmo ainda não era comercializado; ii) algumas empresas do Ceará e de São Paulo alegaram participação em editais recentes, no ano de 2013, ou seja, estavam finalizando o projeto, uma vez que o prazo é de 24 meses a contar da contratação. No entanto, esse último grupo de empresas já havia participado de editais anteriores do PAPPE, de modo que as informações aqui apresentadas não terão maiores problemas para apresentarem os impactos finais do Programa.

As inovações desenvolvidas a partir do projeto aprovado no PAPPE são apresentadas na Tabela 4. A inovação mais significativa está relacionada a um "novo produto para o mercado nacional”, com 88\% das empresas introduzindo um novo produto ou serviço de características únicas no País; $45 \%$ das firmas afirmaram ter desenvolvido inovações de produto para o mercado internacional. A segunda inovação mais desenvolvida está relacionada a "novos processos tecnológicos para o setor de atuação", citada por 57\% das empresas. Além dessas, outras inovações que se destacam são inovações de produto voltadas para as empresas, mas já existentes no mercado, com 42\%, e inovações de processo já existentes no setor de atuação, com $40 \%$.

Fica evidente que as inovações que mais se destacaram são as de produtos e processos, compatibilizando com os objetivos do PAPPE, principalmente quando se mostram como novos produtos e processos para o mercado ou setor de atuação. As demais inovações apresentadas na Tabela 4, sobretudo inovações organizacionais, apresentaram um percentual abaixo de $40 \%$ dentre as empresas analisadas com destaque para "mudanças significativas nos conceitos e/ou práticas de comercialização" com 35\%. No entanto, deve-se destacar que tais inovações são importantes para setores ligados à Tecnologia da Informação, por exemplo. 
Tabela 4 - Resultados do PAPPE (\%)

\begin{tabular}{l|c|c}
\hline \multicolumn{1}{c|}{ Tipo } & Sim & Não \\
\hline Implementação de novos métodos visando atender normas de certificação & $11 \%$ & $89 \%$ \\
\hline Implementação de mudanças significativas de comercialização & $34 \%$ & $66 \%$ \\
\hline Implementação de mudanças significativas de marketing & $29 \%$ & $71 \%$ \\
\hline Implementação de mudanças significativas na estrutura organizacional & $25 \%$ & $75 \%$ \\
\hline Implementação de técnicas avançadas de gestão & $18 \%$ & $82 \%$ \\
\hline Inovações no desenho de produtos & $34 \%$ & $66 \%$ \\
\hline Criação ou melhoria substancial do ponto de vista tecnológico & $22 \%$ & $78 \%$ \\
\hline Processos tecnológicos novos para o setor de atuação & $\mathbf{5 7 \%}$ & $43 \%$ \\
\hline Processos tecnológicos novos para a empresa, mas já existentes no setor & $40 \%$ & $60 \%$ \\
\hline Produto novo para o mercado internacional? & $45 \%$ & $55 \%$ \\
\hline Produto novo para o mercado nacional? & $\mathbf{8 8 \%}$ & $12 \%$ \\
\hline Produto novo para a empresa, mas já existente no mercado? & $42 \%$ & $68 \%$ \\
\hline
\end{tabular}

Fonte: Pesquisa de campo (2015)

A Tabela 5, por sua vez, propõe-se a indicar os resultados obtidos com patenteamento, publicação de artigos, geração de emprego e entrada em novos mercados. Se por um lado, as atividades em P\&D já eram realizadas frequentemente pela maioria das empresas, por outro, as firmas que tinham patente em vigor antes de participar do PAPPE correspondiam a apenas 34\% da amostra. Após o PAPPE, patentes foram registradas por 24 das empresas, com um total de 30 patentes ao todo; deste número apenas quatro delas registrando patentes no exterior. Das empresas que possuíam patentes no período pré-PAPPE, 59\% conseguiram novos registros, enquanto no grupo de empresas que não possuíam, apenas 26\% conseguiram registrar patentes.

Assim como na análise de Carrijo (2011), o Estado de São Paulo apresenta o maior número de empresas que registraram patentes, com 6. Conforme Carrijo e Botelho (2013), o desempenho paulista pode estar relacionado com o ambiente inovativo mais desenvolvido encontrado na região, afirmando as especificidades dos sistemas regionais de inovação. Ademais, deve-se considerar que o fato de o PAPPE ser a terceira etapa de um programa de apoio (PIPE, fase I e II) pode ser um fator explicativo para tal resultado, uma vez que essas empresas contam com um maior período de estímulo financeiro. Outros estados que se destacaram no patenteamento foram a Bahia e o Paraná, com 4 e 3 empresas, respectivamente. 
Tabela 5 - Impactos do PAPPE (\%)

\begin{tabular}{|c|c|c|c|c|c|c|c|c|c|c|}
\hline \multirow{3}{*}{ Gerou patentes? } & \multirow[b]{2}{*}{ Não } & \multirow[b]{2}{*}{ Sim } & \multicolumn{5}{|c|}{ Quantidade } & \multicolumn{3}{|c|}{ Localização } \\
\hline & & & 1 & 2 & 3 & 4 & 5 ou mais & Brasil & Exterior & $\begin{array}{l}\text { Brasil e } \\
\text { exterior }\end{array}$ \\
\hline & $63 \%$ & $37 \%$ & $79 \%$ & $17 \%$ & $4 \%$ & $0 \%$ & $0 \%$ & $83 \%$ & $4 \%$ & $13 \%$ \\
\hline \multirow{3}{*}{ Gerou artigos? } & \multirow[b]{2}{*}{ Não } & \multirow[b]{2}{*}{ Sim } & \multicolumn{5}{|c|}{ Quantidade } & \multicolumn{3}{|c|}{ Localização } \\
\hline & & & 1 & 2 & 3 & 4 & 5 ou mais & Brasil & Exterior & $\begin{array}{l}\text { Brasil e } \\
\text { exterior }\end{array}$ \\
\hline & $65 \%$ & $35 \%$ & $23 \%$ & $42 \%$ & $4 \%$ & $4 \%$ & $27 \%$ & $53 \%$ & $12 \%$ & $35 \%$ \\
\hline \multirow{3}{*}{$\begin{array}{l}\text { Gerou novos } \\
\text { empregos? }\end{array}$} & \multirow{2}{*}{ Não } & \multirow{2}{*}{ Sim } & \multicolumn{8}{|c|}{ Quantidade } \\
\hline & & & 1 & 2 & 3 & 4 & 5 & entre 6 e 15 & entre 11 e 15 & Mais de 15 \\
\hline & $32 \%$ & $68 \%$ & $15 \%$ & $29 \%$ & $20 \%$ & $9 \%$ & $7 \%$ & $16 \%$ & $2 \%$ & $2 \%$ \\
\hline \multirow{3}{*}{$\begin{array}{l}\text { Inseriu-se em novo } \\
\text { mercado? }\end{array}$} & \multirow[b]{2}{*}{ Não } & \multirow[b]{2}{*}{ Sim } & \multicolumn{8}{|c|}{ Localização } \\
\hline & & & \multicolumn{2}{|c|}{$\begin{array}{c}\text { Local } \\
\text { Regional }\end{array}$} & \multicolumn{2}{|c|}{ Estadual } & \multicolumn{2}{|c|}{ Nacional } & \multicolumn{2}{|c|}{ Externo } \\
\hline & $28 \%$ & $72 \%$ & \multicolumn{2}{|c|}{$18 \%$} & \multicolumn{2}{|c|}{$5 \%$} & \multicolumn{2}{|c|}{$67 \%$} & \multicolumn{2}{|c|}{$10 \%$} \\
\hline
\end{tabular}

Fonte: Pesquisa de campo (2015)

Um baixo número de empresas alegou ter gerado artigos, apenas 35\% delas. A maior parte conseguiu criar dois artigos, 42\% das empresas, seguido de $27 \%$ delas criando 5 ou mais publicações a respeito do projeto/setor de atuação. Há uma participação considerável de artigos publicados no exterior, com $12 \%$ deles apenas no exterior e 35\% conseguindo artigos no Brasil e no exterior.

A inserção em um novo mercado foi conquistada por $72 \%$ das firmas, sobretudo em nível nacional, o que está alinhado com as inovações de produto para o mercado nacional, como destacado anteriormente. Sendo assim, pode-se sugerir que as inovações geradas a partir do PAPPE além de serem em grande maioria associada a novos produtos para o mercado nacional, foram capazes de induzir as empresas à conquista de novos mercados fora de seus estados. São impactos como esses que se espera das empresas brasileiras, sobretudo daquelas que participam de programas de fomento.

No universo da PINTEC, no período $2009-2011$ a taxa de geral de inovação foi de $35,7 \%{ }^{6}$, com queda na taxa de inovação na Indústria em relação à PINTEC 2008, de 38,1\% de empresas inovadoras para 35,6\%. Já no setor de Serviços, 36,8\% das empresas inovaram. Na Indústria, percebe-se a uma predominância de empresas inovando apenas em processo (18,3\%), seguidas pelas inovadoras em produtos e processos $(13,4 \%)$, enquanto nos Serviços, predominaram empresas que inovaram tanto em produto quando em processo (21,8\%), seguidas das inovativas apenas em processo (9,7\%). Com 81,7\%, o setor de Pesquisa e desenvolvimento apresentou maior incidência de inovação de processo.

No Brasil, as edições anteriores da PINTEC mostraram que as inovações de processo sempre predominaram em relação às de produto. [...]. Deste modo, a Pintec 2011 torna a revelar um comportamento similar ao apresentado nas pesquisas anteriores em relação à avaliação qualitativa das empresas no que diz respeito às atividades inovativas empreendidas por elas para viabilizar suas inovações. Mais uma vez, mantém-se o padrão de inovação baseado no acesso ao conhecimento tecnológico através da incorporação de máquinas e equipamentos, que figura como a atividade considerada de importância alta ou média para 73,5\% das empresas inovadoras pertencentes ao âmbito da pesquisa. Na sequência, figura a atividade, muitas vezes complementar, de treinamento (59,5\%) e a aquisição de software, onde 33,2\% das empresas a consideram como atividade de média ou alta relevância no período 2009-2011. (PINTEC, 2011, p. 44).

As empresas da amostra desta pesquisa já inovavam em produto e/ou processo, tendo resultados satisfatórios nos impactos apresentados, com exceção para inserção no mercado externo. A Tabela 4, apresentando os resultados inovativos do PAPPE, mostrou que para produto novo para o mercado nacional e processo tecnológico novo para o setor de atuação, a taxa da inovação é robusta, alcançando

\footnotetext{
${ }^{6}$ Conforme aponta a publicação da PINTEC 2011, este número não pode ser comparado com as edições anteriores, uma vez que na PINTEC 2005 e na PINTEC 2008 foram incorporadas no setor de serviços de P\&D, além de entidades empresariais, aquelas organizadas juridicamente como administração pública e como entidades sem fins lucrativos. Já na PINTEC 2011, procura-se seguir mais estritamente as recomendações do Manual de Oslo, considerando apenas os resultados pertinentes a entidades empresariais.
} 
$88 \%$ e $57 \%$, respectivamente. Outras inovações com destaque foram produto novo para o mercado internacional (45\%) e produto novo para empresa, mas já existente no mercado (42\%) e processos tecnológicos novos para a empresa, mas já existentes no setor (40\%). Percebe-se aqui um padrão diferente do que é observado no universo da PINTEC, que demonstra uma predominância das inovações de processo em relação às inovações de produto.

As empresas participantes do PAPPE demonstram um melhor desempenho em relação às inovações de produto, algo que também foi observado na pesquisa de Carrijo (2011), principalmente em relação a produtos não existentes no mercado. Conforme aponta a publicação da PINTEC (2011), a inovação de produto tende a exigir maiores esforços inovativos por parte da empresa ${ }^{7}$, "assim como a exercer capacidade de trazer inovações de processo” (PINTEC, 2011, p. 39).

Uma vez que a inovação de produto tende a exigir maiores esforços inovativos por parte das empresas, a política do PAPPE justifica-se no apoio a projetos cooperativos de maior risco, custo e incerteza, capazes de criarem novos produtos. Considerando os graus de incerteza associados a vários tipos de inovações, o PAPPE tem sido capaz de atuar para que as empresas lidem com todos os níveis de incerteza, conforme os listados por Freeman e Soete (2008), principalmente em níveis mais altos. Esse tipo de financiamento age ainda para as empresas superarem o risco tecnológico presente na fase de P\&D do processo inovativo, não sendo capaz de agir contra o risco de mercado ou gerencial. Nesse último encontram-se, por exemplo, a falta de pessoal qualificado, tomada de decisões equivocadas, desenvolvimento do projeto e alocação de recursos de maneira incompatível, dentre outros. A capacitação de mão de obra é importante para a condução da inovação, algo que no cenário brasileiro as empresas destacam como uma das grandes dificuldades a serem enfrentadas, devido à falta de profissionais capacitados no País.

\subsection{Cooperação}

Segundo pesquisas conduzidas em diversos países, as empresas que estabelecem relações de cooperação com outros agentes do sistema de inovação tendem a investir mais em gastos com inovação se comparadas àquelas que não cooperam (OEDC, 2010). Ademais, percebe-se uma tendência crescente nos países da OECD para cooperação entre empresas inovativas e clientes/consumidores, como uma maneira das firmas explorarem novas oportunidades e diminuírem seus custos, em que a interação entre oferta e demanda facilite o processo inovativo.

De acordo com a publicação da PINTEC 2011, os indicadores de informação para a inovação de produto e processo atribuídos pelas empresas brasileiras em nível relevante (médio ou alto) diferenciamse de acordo com os recortes setoriais. Para a Indústria, as redes de informação informatizadas representam a principal fonte de informação, com 75,5\%. Para o setor de Eletricidade e gás e setor de Serviços, esse valor é de $82,1 \%$ e $79,8 \%$, respectivamente.

Os fornecedores são fontes relevantes de informação para os setores de Eletricidade e gás e Indústria, com percentuais de 79,7\% e 70,3\%, respectivamente, “o que parece ser compatível com o caráter central da atividade inovativa representada pela aquisição de máquinas e equipamentos para esses setores” (PINTEC, 2011, p. 53). Se, por um lado, o setor de Serviços apresenta 54,3\% das empresas que consideram os fornecedores de alta ou média importância, por outro, os clientes se destacam como relevantes fontes de informações para o setor, para cerca de 73,3\% das firmas. Para a Indústria, os clientes são importantes para 65,9\%, enquanto o setor de Eletricidade e gás apresenta um valor bem abaixo, com 19,2\%.

Em relação à cooperação, a PINTEC 2011 aponta para o crescimento de 10,1\% para 15,9\% das empresas industriais que haviam cooperado com algum tipo de parceiro, se comparado ao período da PINTEC 2008. Os dados da pesquisa ainda apontam para patamares mais acentuados de cooperação correspondendo ao maior porte das empresas, em todos os setores. Na Indústria, por exemplo, no período correspondente a 2009-2011, apenas 13,1\% das empresas inovadoras que possuíam até 49 pessoas ocupadas cooperaram, enquanto para as empresas inovadoras com mais de 500 pessoas ocupadas o percentual foi de 48,6\%. Dentre as firmas de grande porte do setor de Eletricidade e gás, 94,7\% se

\footnotetext{
${ }^{7}$ Não se deve perder de vista, contudo, a existência de padrões setoriais, cuja trajetória tecnológica é fundamentalmente baseada em inovação de processo (PINTEC, 2011, p.39).
} 
envolveram em arranjos cooperativos, enquanto nas pequenas o valor foi de 36,8\%; destaca-se assim, níveis de cooperação mais robustos para esse setor. Já para o setor de Serviços, os percentuais foram maiores do que os observados na Indústria, com 23,8\% das firmas cooperando no período analisado, embora o valor tenha sido próximo ao setor industrial quando analisadas as grandes firmas, com $47 \%$ delas tendo realizado alguma cooperação.

Dentre os parceiros mais importantes para os setores figuram: i) Indústria (fornecedores, 76,5\% e clientes/consumidores, 59,4\%); ii) Serviços (empresas de consultoria, 62,5\% e clientes ou consumidores, 46,2\%); iii) Eletricidade e gás (universidades ou institutos de pesquisa, 70,4\%). Em relação ao último setor, compatibiliza-se com "o fato de ser um segmento econômico relativamente mais intenso na aquisição externa de P\&D” (PINTEC, 2011, p. 55).

As Tabela 6 e 7 reúnem os principais parceiros das firmas antes da participação no PAPPE e criação de novos relacionamento devido a execução do projeto no Programa. Dentre os tipos de relacionamentos sugeridos, apenas 3 ocorriam com frequência no período pré-PAPPE: cooperação com "universidades", com "fornecedores" e com "clientes"; os dois últimos apresentando-se como relacionamentos frequentes em mais da metade das empresas entrevistadas, com 60\% e 58\%, respectivamente. As Tabelas 6 e 7 ainda mostram o grau de importância dado pela firma, a formalização e a localização do parceiro, antes e após a participação no Programa. Dentre as novas relações de cooperação criadas, apenas 3 apresentaram um percentual acima de 50\% dentre as empresas analisadas, com fornecedores (58\%), clientes (62\%) e sobretudo universidades, com 71\%.

Em relação às universidades, apenas $23 \%$ das firmas alegaram que não desenvolviam relacionamentos com esses agentes, enquanto 32\% o faziam de maneira ocasional. Já em relação aos institutos de pesquisa, parte significativa das empresas, cerca de $46 \%$, não mantinham nenhum tipo de relacionamento. No entanto, das empresas que alegaram cooperação do tipo empresa-IPP o maior número mantinha um relacionamento frequente. Assim, fica evidente o interesse das empresas por relacionamentos do tipo setor produtivo-ciência, embora o direcionamento seja mais para as universidades do que para os institutos de pesquisa.

Os dados analisados mostram que o PAPPE tende mais a fortalecer as relações de cooperação com agentes com os quais já se mantinha um relacionamento frequente do que a buscar por novas parcerias, o que reforça os resultados encontrados em pesquisa anterior de Carrijo (2011) sintetizados em Carrijo e Botelho (2013). É importante destacar que do conjunto de empresas que passou a cooperar a partir do apoio do PAPPE o fez majoritariamente com clientes, fornecedores e universidades.

Desse modo, pode-se dizer que as empresas participantes já mantinham um padrão cooperativo e o programa foi capaz de contribuir com o fortalecimento de relacionamentos nos quais há uma troca de informações mais natural, objetiva e direcionada, ou seja, cooperação com agentes que estejam alinhados mais aos objetivos do programa, a criação de inovação de produtos e processos.

Os resultados encontrados na pesquisa, considerando-se apenas os relacionamentos frequentes (pré-PAPPE, Tabela 6), apontam para uma semelhança com as empresas do universo da PINTEC, sobretudo no tocante à cooperação com clientes e fornecedores. 


\begin{tabular}{|c|c|c|c|c|c|c|c|c|c|c|c|c|c|c|c|}
\hline \multirow{3}{*}{ Agentes } & \multicolumn{6}{|c|}{ Pré-PAPPE } & \multicolumn{9}{|c|}{ PAPPE } \\
\hline & \multicolumn{3}{|c|}{ Grau de frequência } & \multicolumn{3}{|c|}{ Formalização } & \multicolumn{2}{|c|}{$\begin{array}{c}\text { Novo } \\
\text { relacionamento? }\end{array}$} & \multicolumn{4}{|c|}{ Grau de importância } & \multicolumn{3}{|c|}{ Formalização } \\
\hline & N.O. & RR. & FQ. & Formal & Informal & Ambos & Não & $\operatorname{Sim}$ & I. & P.R. & $\mathrm{R}$. & M.R. & Formal & Informal & Ambos \\
\hline Joint venture & $74 \%$ & $17 \%$ & $9 \%$ & $65 \%$ & $35 \%$ & $0 \%$ & $89 \%$ & $11 \%$ & $0 \%$ & $0 \%$ & $86 \%$ & $14 \%$ & $86 \%$ & $14 \%$ & $0 \%$ \\
\hline Fornecedores & $22 \%$ & $18 \%$ & $60 \%$ & $67 \%$ & $16 \%$ & $17 \%$ & $42 \%$ & $58 \%$ & $0 \%$ & $8 \%$ & $68 \%$ & $24 \%$ & $58 \%$ & $24 \%$ & $18 \%$ \\
\hline Clientes & $28 \%$ & $14 \%$ & $58 \%$ & $57 \%$ & $17 \%$ & $26 \%$ & $38 \%$ & $62 \%$ & $3 \%$ & $5 \%$ & $45 \%$ & $48 \%$ & $47 \%$ & $28 \%$ & $25 \%$ \\
\hline Concorrentes & $60 \%$ & $32 \%$ & $8 \%$ & $15 \%$ & $58 \%$ & $27 \%$ & $77 \%$ & $23 \%$ & $0 \%$ & $42 \%$ & $50 \%$ & $8 \%$ & $46 \%$ & $38 \%$ & $16 \%$ \\
\hline Universidades & $23 \%$ & $32 \%$ & $45 \%$ & $56 \%$ & $26 \%$ & $18 \%$ & $29 \%$ & $71 \%$ & $0 \%$ & $9 \%$ & $63 \%$ & $28 \%$ & $59 \%$ & $13 \%$ & $28 \%$ \\
\hline Inst. Pesquisa & $46 \%$ & $20 \%$ & $34 \%$ & $47 \%$ & $24 \%$ & $29 \%$ & $72 \%$ & $28 \%$ & $0 \%$ & $6 \%$ & $67 \%$ & $27 \%$ & $50 \%$ & $11 \%$ & $39 \%$ \\
\hline Representação & $69 \%$ & $17 \%$ & $14 \%$ & $65 \%$ & $15 \%$ & $20 \%$ & $86 \%$ & $14 \%$ & $0 \%$ & $33 \%$ & $56 \%$ & $11 \%$ & $67 \%$ & $33 \%$ & $0 \%$ \\
\hline Entidades Sindicais & $66 \%$ & $25 \%$ & $9 \%$ & $84 \%$ & $16 \%$ & $0 \%$ & $91 \%$ & $9 \%$ & $34 \%$ & $33 \%$ & $33 \%$ & $0 \%$ & $100 \%$ & $0 \%$ & $0 \%$ \\
\hline Inst. apoio e promoção & $60 \%$ & $18 \%$ & $22 \%$ & $77 \%$ & $15 \%$ & $8 \%$ & $78 \%$ & $22 \%$ & $15 \%$ & $0 \%$ & $64 \%$ & $21 \%$ & $64 \%$ & $0 \%$ & $36 \%$ \\
\hline Agentes financeiros & $46 \%$ & $37 \%$ & $17 \%$ & $89 \%$ & $3 \%$ & $8 \%$ & $75 \%$ & $25 \%$ & $0 \%$ & $0 \%$ & $63 \%$ & $37 \%$ & $69 \%$ & $6 \%$ & $25 \%$ \\
\hline $\begin{array}{l}\text { Instituições de testes, } \\
\text { ensaios e certificações }\end{array}$ & $67 \%$ & $22 \%$ & $11 \%$ & $100 \%$ & $0 \%$ & $0 \%$ & $72 \%$ & $28 \%$ & $0 \%$ & $17 \%$ & $50 \%$ & $33 \%$ & $78 \%$ & $6 \%$ & $16 \%$ \\
\hline $\begin{array}{l}\text { Centros de capacitação } \\
\text { profissional de assistência } \\
\text { técnica e de manutenção }\end{array}$ & $71 \%$ & $23 \%$ & $6 \%$ & $63 \%$ & $37 \%$ & $0 \%$ & $86 \%$ & $14 \%$ & $0 \%$ & $33 \%$ & $44 \%$ & $23 \%$ & $66 \%$ & $0 \%$ & $34 \%$ \\
\hline
\end{tabular}

Fonte: Pesquisa de campo (2015)

Nota 1: Em grau de frequência (N.O. - Não ocorriam; RR. - Raramente; FQ. - Frequentemente)

Nota 2: Em grau de importância (I. - Irrelevante; P.R. - Pouco relevante; R. - Relevante; M.R. - Muito Relevante) 
Tabela 7 - Localização dos principais parceiros - períodos pré-PAPPE e PAPPE (\%)

\begin{tabular}{|c|c|c|c|c|c|c|c|c|c|c|}
\hline \multirow{2}{*}{ Agentes } & \multicolumn{5}{|c|}{ Pré-PAPPE } & \multicolumn{5}{|c|}{ PAPPE } \\
\hline & Local & Regional & Estadual & Nacional & Externo & Local & Regional & Estadual & Nacional & Externo \\
\hline Joint venture & $19 \%$ & $19 \%$ & $13 \%$ & $48 \%$ & $1 \%$ & $29 \%$ & $13 \%$ & $29 \%$ & $29 \%$ & $0 \%$ \\
\hline Fornecedores & $21 \%$ & $12 \%$ & $10 \%$ & $51 \%$ & $6 \%$ & $10 \%$ & $19 \%$ & $6 \%$ & $52 \%$ & $13 \%$ \\
\hline Clientes & $17 \%$ & $11 \%$ & $11 \%$ & $57 \%$ & $4 \%$ & $3 \%$ & $15 \%$ & $6 \%$ & $76 \%$ & $0 \%$ \\
\hline Concorrentes & $12 \%$ & $12 \%$ & $8 \%$ & $45 \%$ & $23 \%$ & $27 \%$ & $9 \%$ & $0 \%$ & $63 \%$ & $0 \%$ \\
\hline Universidades & $20 \%$ & $18 \%$ & $30 \%$ & $30 \%$ & $2 \%$ & $23 \%$ & $13 \%$ & $33 \%$ & $31 \%$ & $0 \%$ \\
\hline Instituto de Pesquisa & $11 \%$ & $20 \%$ & $26 \%$ & $43 \%$ & $0 \%$ & $22 \%$ & $11 \%$ & $28 \%$ & $33 \%$ & $0 \%$ \\
\hline Representação & $21 \%$ & $37 \%$ & $16 \%$ & $26 \%$ & $0 \%$ & $33 \%$ & $22 \%$ & $0 \%$ & $44 \%$ & $0 \%$ \\
\hline Entidades Sindicais & $19 \%$ & $14 \%$ & $24 \%$ & $43 \%$ & $0 \%$ & $22 \%$ & $6 \%$ & $0 \%$ & $72 \%$ & $0 \%$ \\
\hline Inst. apoio e promoção & $15 \%$ & $5 \%$ & $20 \%$ & $60 \%$ & $0 \%$ & $11 \%$ & $11 \%$ & $11 \%$ & $56 \%$ & $11 \%$ \\
\hline Agentes financeiros & $59 \%$ & $9 \%$ & $23 \%$ & $9 \%$ & $0 \%$ & $33 \%$ & $33 \%$ & $17 \%$ & $17 \%$ & $0 \%$ \\
\hline $\begin{array}{l}\text { Instituições de testes, ensaios e } \\
\text { certificações }\end{array}$ & $38 \%$ & $8 \%$ & $27 \%$ & $27 \%$ & $0 \%$ & $21 \%$ & $21 \%$ & $21 \%$ & $37 \%$ & $0 \%$ \\
\hline $\begin{array}{l}\text { Centros de capacitação } \\
\text { profissional de assistência técnica } \\
\text { e de manutenção }\end{array}$ & $31 \%$ & $6 \%$ & $29 \%$ & $34 \%$ & $0 \%$ & $25 \%$ & $13 \%$ & $19 \%$ & $43 \%$ & $0 \%$ \\
\hline
\end{tabular}

Fonte: Pesquisa de campo (2015) 
Em relação à influência do PAPPE na criação e ou fortalecimento de elos entre as empresas e outros agentes (capazes de estarem associados ao processo inovativo), os dados da Tabela 8 nos mostram que, quanto maior o grau de frequência dos relacionamentos previamente estabelecidos, maior tende a ser o número de empresas que criam novos relacionamentos com seus parceiros. O relacionamento com universidades foi o mais expressivo dentre todos os tipos de interações, com $90 \%$ das empresas que mantinham relacionamentos frequentes criando novas cooperações, enquanto a relação com institutos de pesquisa foi fortalecida por $55 \%$ das empresas que se relacionavam com esses agentes no mesmo grau de frequência. Esse aspecto corrobora resultados de outras pesquisas que indicam o caráter de longo prazo desse tipo de interação.

Tabela 8 - Novos relacionamentos mediante frequência pré-PAPPE por tipo de agente (\%)

\begin{tabular}{|c|c|c|c|c|c|}
\hline \multicolumn{2}{|c|}{ Joint Venture } & \multicolumn{2}{|c|}{ Fornecedores } & \multicolumn{2}{|c|}{ Clientes } \\
\hline Pré-PAPPE & Pós-PAPPE & Pré-PAPPE & Pós-PAPPE & Pré-PAPPE & Pós-PAPPE \\
\hline Não ocorriam & $8 \%$ & Não ocorriam & $29 \%$ & Não ocorriam & $39 \%$ \\
\hline Raramente & $9 \%$ & Raramente & $67 \%$ & Raramente & $78 \%$ \\
\hline Frequentemente & $40 \%$ & Frequentemente & $67 \%$ & Frequentemente & $68 \%$ \\
\hline \multicolumn{2}{|c|}{ Concorrentes } & \multicolumn{2}{|c|}{ Universidades } & \multicolumn{2}{|c|}{ Institutos de Pesquisa } \\
\hline Pré-PAPPE & Pós-PAPPE & Pré-PAPPE & Pós-PAPPE & Pré-PAPPE & Pós-PAPPE \\
\hline Não ocorriam & $15 \%$ & Não ocorriam & $47 \%$ & Não ocorriam & $17 \%$ \\
\hline Raramente & $33 \%$ & Raramente & $71 \%$ & Raramente & $23 \%$ \\
\hline Frequentemente & $40 \%$ & Frequentemente & $90 \%$ & Frequentemente & $55 \%$ \\
\hline
\end{tabular}

Fonte: Pesquisa de campo (2015)

Analisando especificamente a cooperação com a base científica, a segunda fase da pesquisa foi capaz de apontar alguns aspectos mais qualitativos sobre esse tipo de relacionamento. A empresa Alfa, uma empresa baiana do segmento de produtos alimentícios e bebidas, utilizou recursos do PAPPE para contratação de serviços de planejamento e controle de produção com o Campus Integrado de Manufatura e Tecnologia do Serviço Nacional de Aprendizagem Industrial (SENAI-CIMATEC), além de ter colaborado com pesquisadores da Universidade Federal da Bahia (UFBA) e do Instituto Federal da Bahia (IFBA) para o desenvolvimento de seu projeto ${ }^{8}$. A empresa criou um grupo de pesquisa, a partir da captação de recursos do Programa de Formação de Recursos Humanos em Áreas Estratégicas (RHAE), que concede bolsas para pesquisadores inserirem-se no setor produtivo, desenvolvendo um estudo do sistema local de produção. Junto ao grupo de pesquisa a Alfa mapeia o sistema local de produção, além de levantar dados econômicos das atividades a fim de verificar se na sua região há indicadores de identificação geográfica, algo que poderá trazer benefícios tanto para a empresa quanto para fornecedores e clientes.

A empresa Beta, empresa paraibana do segmento de informática e serviços relacionados, por sua vez, aponta como a principal dificuldade para o desenvolvimento do seu projeto a contratação de pessoa especializada na sua área, que tivesse expertise necessária para o desenvolvimento do seu projeto. A empresa informou que possui muitos profissionais ligados à área de TI, de engenharia de software, mas não especificamente na plataforma de desenvolvimento utilizada. Ainda assim, a firma conseguiu captar um profissional do Instituto Federal da Paraíba (IFPB) de sua região que desenvolveu o projeto junto à empresa, transferindo conhecimento que posteriormente ficou retido na empresa. O produto criado pela empresa já sofre alterações há 13 anos, e após a participação no PAPPE a inovação gerada conseguiu impactar outros projetos. Atualmente a empresa desenvolve com recursos do TECNOVA um novo projeto, melhoria deste mesmo produto a partir de cooperação com a Universidade Federal de Campina Grande (UFCG).

\footnotetext{
${ }^{8}$ A Alfa é uma empresa que produz licores, e seu projeto estava centrado no desenvolvimento de equipamentos específicos para a produção com a matéria-prima utilizada, frutas típicas da região onde a empresa está localizada.
} 
A Delta, uma empresa gaúcha de fabricação de equipamentos de sistemas médicos, por sua vez, manteve relações com a Universidade Federal de Santa Catarina (UFSC) e a Pontifícia Universidade Católica do Rio Grande do Sul (PUC-RS) a partir de contratações de pesquisas onde não tem expertise e de serviço por não possuir equipamentos de medida adequados, sendo inviável uma compra devido ao período curto de utilização. Segundo o próprio coordenador da empresa, as relações com esses agentes foram iniciadas ou potencializadas a partir da participação no PAPPE, e a empresa continua a utilizá-las mesmo sem os recursos públicos. Ademais, a empresa pode fazer intercâmbio de funcionários com uma das universidades, buscando novos conhecimentos e capacitação de pessoal ocupado.

As outras empresas participantes da segunda fase foram a Beta e a Épsilon i) a primeira, uma empresa de P\&D voltado para biotecnologia, declarou desenvolver parcerias com universidades constantemente a partir de intercâmbio de pesquisadores, de seu pessoal ocupado com pesquisadores de grupos de pesquisa; ii) a segunda, uma empresa de TI, foi a única a declarar não manter nenhuma cooperação com universidades ou institutos de pesquisa devido à burocracia e lentidão dessas instituições.

As relações de cooperação universidade-empresa desenvolvidas a partir do PAPPE, direta ou indiretamente, apontam para aspectos encontrados na literatura. O primeiro, diz respeito ao acesso aos fundos de pesquisa capaz de diminuir os riscos e incertezas das atividades de pesquisa com outros agentes (NOVELI; SEGATTO, 2012; SEGATTO-MENDES; SBRAGIA, 2002). A contratação de serviços e/ou desenvolvimento de pesquisas conjuntas que exigem maior risco para empresas de micro e pequeno porte mostram-se como os principais tipos de relações U-E que programas como o PAPPE podem incidir. O segundo, aponta para a localização geográfica. Conforme apresentando na Tabela 7, o relacionamento com universidades tende a ter uma significativa presença no nível estadual ${ }^{9}$. Autores como Garcia et al. (2011) e Noveli e Segatto (2012) apontam para a importância da proximidade geográfica para o fomento de relações universidade-empresa a partir da criação de canais específicos de comunicação. Outro aspecto que deve diz respeito aos contatos informais entre o pessoal das empresas e a base científica, podendo estimular o relacionamento entre esses dois tipos de agentes (DALMARCO, 2012; NOVELI; SEGATTO, 2012).

\section{Conclusão}

A partir do reconhecimento das políticas públicas voltadas para o fomento à inovação no cenário brasileiro, este trabalho teve como objetivo avaliar uma linha de financiamento público a projetos inovadores, o PAPPE. A partir da pesquisa desenvolvida pode-se observar diferentes aspectos relacionados às empresas beneficiadas e aos impactos observados.

Dentre os principais resultados, a pesquisa aponta para a criação de "novo produto para o mercado nacional” e "novo processo tecnológico para o setor de atuação”. Diferenciando-se do padrão apontado pelas publicações da PINTEC sobre como as empresas brasileiras inovam, observou-se uma predominância das inovações de produto sobre as inovações de processo, ainda que essas últimas também tenham tido resultados satisfatórios.

Tais resultados acompanham o que se observou na análise de Carrijo (2011), principalmente quanto à capacidade das empresas em inovarem para o setor de atuação, e não apenas "para dentro", a partir da aquisição de máquinas e equipamentos, conforme apontam as publicações da PINTEC. Uma vez que a inovação de produto tende a exigir maiores esforços inovativos por parte das empresas, especialmente em P\&D, a política do PAPPE justifica-se no apoio a projetos cooperativos de maior risco, custo e incerteza, capazes de criarem novos produtos.

Se considerarmos os diferentes graus de incerteza encontrados em vários tipos de inovações, conforme a proposição de Freeman e Soete (2008), as empresas foram capazes de lidar com níveis mais altos de incerteza. Esse tipo de financiamento age ainda para as empresas superarem o risco tecnológico

\footnotetext{
${ }^{9}$ A relação com agentes em nível nacional de forma mais significativa pode estar ligada à busca de expertises que a empresa não possui e que possivelmente não encontra em sua região. De todo modo, as relações com universidades indicaram a importância da proximidade geográfica, de maneira que a busca por agentes fora de sua região parece ocorrer de forma complementar às interações desenvolvidas no local, o que se observou nas empresas Alfa, Beta e Delta.
} 
presente na fase de $P \& D$ do processo inovativo, não sendo capaz de agir contra o risco de mercado ou gerencial, para o que seriam necessários instrumentos específicos.

Dessa maneira, tais esforços justificariam, em parte, o engajamento em projetos cooperativos de maior risco, custo e incerteza, sobretudo com apoio governamental, conforme apontam as análises de Rapini et al. (2014) e Rapini et al. (2015). Portanto, as empresas participantes do PAPPE, com um perfil mais colaborativo, sobretudo com universidades/institutos de pesquisa, conseguem suprir a necessidade de maiores esforços, que lhe trariam maior risco, a partir da captação de recursos públicos. Como resultado, tem-se uma maior incidência de inovações de produto, diferenciando-se, em parte, das suas congêneres.

Em relação às dificuldades enfrentadas pelas empresas, a pesquisa mostra que as dificuldades mais importantes encontradas pelas empresas para o desenvolvimento do projeto são a "falta de mão de obra qualificada" e a "demora na liberação dos recursos financeiros”. As empresas entrevistadas destacam que a burocracia durante a participação no Programa é um dos maiores obstáculos a serem superados, que, por vezes, pode interromper o andamento do projeto.

Outro problema destacado pelas empresas seria, além do atraso na liberação dos recursos, o corte dos mesmos quando repassados pela FAP. Isso, consequentemente, afeta o projeto da empresa, podendo comprometer sua capacidade de inovar. No entanto, de modo geral, as empresas consideram que vale a pena enfrentar os entraves burocráticos dos programas de financiamento público, destacando a importância de instrumentos como o PAPPE para o setor produtivo brasileiro.

Por fim, a pesquisa contribui com a avaliação de recentes mudanças observadas na política de inovação brasileira, cuja literatura ainda é bastante escassa, especialmente a que se baseia em dados primários obtidos nas empresas apoiadas pelas linhas de fomento.

\section{Referências Bibliográficas}

ALBUQUERQUE, E. M.; Estruturas financeiras, funcionalidade e sistemas de inovação: notas introdutórias sobre uma articulação necessária. Nova Economia. Belo Hozizonte, v. 6, n;2, p. 113-132, 1996.

Catching up no século XXI: construção combinada de sistemas de inovação e de bem-estar social. Crescimento Econômico: Estratégias e Instituições, IPEA, pp. 55-83, 2009.

IBGE. Pesquisa de inovação tecnológica (PINTEC, 2008). Rio de Janeiro, 2010.

Pesquisa de inovação tecnológica (PINTEC, 2011). Rio de Janeiro, 2013.

CARRIJO, M. C. Inovação e relações de cooperação: uma análise sobre o Programa de Apoio à Pesquisa em Empresas (PAPPE). 2011. 216 f. Tese de Doutorado em Economia, com concentração em Políticas

Públicas e Desenvolvimento Econômico - Programa de Pós-Graduação em Economia. Universidade Federal de Uberlândia, Uberlândia.

CARRIJO, M. C.; BOTELHO, M. R. A. Cooperação E inovação: uma análise dos resultados do Programa de Apoio à Pesquisa em Empresas (PAPPE). Revista Brasileira de Inovação, Campinas (SP), 12 (2), p. 417-448, julho/dezembro 2013.

CASSIOLATO, J. E.; RAPINI, M. S.; BITTENCOURT, P. A relação Universidade-indústria no Sistema Nacional de Inovação Brasileiro: uma síntese do debate e perspectivas recentes. Research paper 11/07. RedeSist - Instituto de Economia, Universidade Federal do Rio de Janeiro, Brasil. 
CORDER, S. Financiamento e incentivos ao sistema de ciência, tecnologia e inovação no Brasil: quadro atual e perspectivas. 2004. 234 f. Tese (Doutorado em Política Científica e Tecnológica)-Universidade Estadual de Campinas, Campinas, 2004.

DALMARCO, G. Fluxo de conhecimento na interação universidade-empresa: uma análise de setores tradicionais e de alta tecnologia no Brasil e na Holanda. 2012. 191 f. Tese (Doutorado em Administração) - Programa de Pós-graduação em Administração, Escola de Administração, Universidade Federal do Rio Grande do Sul, Porto Alegre. 2012.

EDQUIST, C. (2006) Systems of Innovation: perspectives and challenges. FARBERGER, J.; MOWERY, D.C.; Nelson, R. (orgs.)The Oxford Handbook of Innovation. Oxford University Press.

ETZKOWITZ, $\mathrm{H}$. The norms of entrepreneurial science: cognitive effects of the new university-industry linkages. Research Policy, 27(8), p. 823-833, 1998.

ETZKOWITZ, H. Hélice Tríplice: Universidade-Indústria-Governo: Inovação em Movimento. Porto Alegre: EDIPUCRS, 2009.

ETZKOWITZ, H.; LEYDESDORFF, L. The dynamics of innovation: from national systems and "mode 2" to a triple helix of university-industry-government relations. Research Policy, 29(2), p. 109-123, 2000.

FREEMAN, C. Technology Policy and Economic Performance: Lessons from Japan, Pinter, London, 1987.

FREEMAN, C.; SOETE, L. A Economia da Inovação Industrial. Clássicos da Inovação. Editora UNICAMP, 2008.

GARCIA, R.; ARAÚJO, V. C.; MASCARINI, S.; SANTOS, E. G. Os efeitos da proximidade geográfica para o estímulo da interação universidade-empresa. Revista de Economia, v. 37, n. especial, p. 307-330, 2011. Editora UFPR.

IBGE. Pesquisa de inovação tecnológica Pesquisa de inovação tecnológica (PINTEC, 2008). Rio de Janeiro, 2010.

Pesquisa de inovação tecnológica (PINTEC, 2011). Rio de Janeiro, 2013.

IPIRANGA, A. S. R.; FREITAS, A. A. F.; PAIVA, T. A. O empreendedorismo acadêmico no contexto da interação universidade - empresa - governo. Cadernos Ebape, FGV, 8(4), p. 676-693, 2010.

LIMA, R. J. C.; BAÊTA, A. M. C.; PAIVA, V. P., BAETA-LARA, F. M. C. O Programa de Apoio à Pesquisa em Empresas (PAPPE) e as conexões entre agentes de inovação: estudo em Minas Gerais. III Simpósio Internacional de Gestão de Projetos. II Simpósio Internacional de Inovação e Sustentabilidade. Anais do III SINGEP e II S2IS - São Paulo - 09, 10 e 11/11/2014.

LONGO, W.P.; KRAHE, P.R.; MARINHO, V.M.C. Incentivos governamentais não fiscais: estratégia para fomentar a inovação tecnológica. Rio de Janeiro: FIRJAN, Cadernos de Tecnologia, v.2, 2002.

MAZZUCATO, M. The Entrepreneurial State. DEMOS 2011. Disponível em <http://www.demos.co.uk/files/Entrepreneurial_State_-_web.pdf>. Acesso: Novembro de 2015. 
MOWERY, D. C.; SAMPAT, B. N. Universities in National Innovation Systems, in Fagerberg, J.; Mowery, D.C.; Nelson, R.R. (orgs.), The Oxford Handbook of innovation, Oxford: Oxford University Press, 2006.

NOVELI, M.; SEGATTO, A. P. Processo de cooperação universidade-empresa para a inovação tecnológica em um parquet tecnológico: evidências empíricas e proposição de um modelo conceitual. Revista de Administração e Inovação, São Paulo, v.9, n.1, p.81-105, jan./mar. 2012.

OECD. The Knowledge-based economy. Paris: OECD Publications, 1996.

. Dynamising National Innovation Systems. 2002. Paris: OCDE Publications, 2002.

. Science, Technology and Industry Outlook 2010. Paris: OCDE Publications, 2010.

Science Technology and Industry Scoreboard: Innovation for growth and society 2015. Paris: OCDE Publications, 2015.

PAVITT, K. Sectoral Patterns of Technical Change: towards a taxonomy and a theory. Research Policy, v. 13. 1984.

PLONSKI, G. A. Cooperação empresa-universidade na Ibero-América: estágio atual e perspectivas. Anais do Simpósio de Gestão da Inovação Tecnológica, São Paulo, 1994.

RAPINI, M. S. O Financiamento aos investimentos em inovação no Brasil. 2010. 146 f. Tese (Doutorado em Economia) - Instituo de Economia, Universidade Federal do Rio de Janeiro, Rio de Janeiro. 2010.

Interação Universidade-Empresa no Brasil: Evidência do Diretório dos Grupos de Pesquisa do CNPq. Estudos Econômicos, São Paulo, v.37, n.1, p. 211-233, Janeiro-Março 2007.

RAPINI, M. S.; OLIVEIRA, V.P.; CALIARI, T. Como a interação universidade-empresa é remunerada no Brasil: evidências dos grupos de pesquisa do CNPq. Texto para discussão $n^{0}$ 513. CEDEPLAR, FACE, UFMG. Belo Horizonte. Março de 2015.

RAPINI, M. S.; OLIVEIRA, V. P.; SILVA NETO, F. C. C.. A natureza do financiamento influencia na interação universidade-empresa no Brasil? Revista Brasileira de Inovação, Campinas (SP), 13 (1), p.77108, Janeiro/Junho 2014.

RAPINI, M.; AlBUQUERQUE, E,; CHAVES, C.; SILVA, L.; SOUZA, S.; RIGHI, H.; CRUZ, W. University-industry interactions in an immature system of innovation: evidence from Minas Gerais, Brazil. Science and Public Policy, v. 36, n.5, p. 373-386, 2009.

RIGHI, H. M.; RAPINI, M. S. Metodologia e apresentação da Base de Dados do Censo 2004 do Diretório dos Grupos de Pesquisa do Conselho Nacional de Pesquisa Científica e Tecnológica (CNPq). In: Suzigan, W.; Albuquerque, E. M.; Cario, S. A ; Em busca da inovação: interação universidade-empresa no Brasil. Economia Política e Sociedade. FAPESP, Editora Autêntica, 2011.

SBRAGIA, R. (Coord.) Inovação. Como vencer esse desafio empresarial. São Paulo: Clio Editora, 2006.

SEGATO-MENDES, A. P.; SBRAGIA, R. O processo de cooperação universidade-empresa em universidades brasileiras. Revista de Administração, São Paulo v. 37, n. 4. P.58-71, outubro/dezembro 2002. 
STAL, E.; FUJINO, A. As relações universidade-empresa no Brasil sob a ótica da Lei da Inovação. Cadernos de Pós-Graduação-Administração. São Paulo. v. 4, n. 1, especial RAI, p. 269-283, 2005.

SUZIGAN, W.; ALBUQUERQUE, E. M.; CARIO, S. A. Em busca da inovação: interação universidadeempresa no Brasil. Economia Política e Sociedade. FAPESP, Editora Autêntica, 2011.

WEISZ. J. Mecanismos de apoio à inovação tecnológica. SENAI - Departamento Nacional - 3. ed. Brasília, 2006.

TORRES, P. H. Financiamento à inovação e interação entre atividades científicas e tecnológicas: uma análise a partir do PAPPE. 2016. 195 f. Dissertação (Mestrado em Economia) - Programa de Pósgraduação em Economia, Universidade Federal de Uberlândia, Uberlândia. 2016. 